\title{
The Factors Predicting Quality of Life Among Unemployed Adults: A Model Based on Salutogenic Approach
}

\author{
Marja Hult ${ }^{1}$ D $\cdot$ Anna-Maija Pietilä ${ }^{2} \cdot$ Terhi Saaranen $^{2}$
}

Accepted: 13 August 2020 / Published online: 26 August 2020

(c) The Author(s) 2020

\begin{abstract}
Unemployment narrows the realization of individual potential and has a negative effect on the experiences and status of an individual, thereby weakening the quality of life. We explored meaningfulness, health and work ability as predictors of quality of life among unemployed adults. A total of 30,598 persons participated in nationwide Finnish Regional Health and Well-Being Study $(\mathrm{N}=76,000)$ between January 2014 and January 2015. This study used data from 1158 unemployed or laid-off persons aged 20-65. Developed path model based on the salutogenic approach fitted well to the data. Perceived meaningfulness had the most substantial effect on the quality of life. Good health associated with good work ability and they both had a significant impact on the quality of life. Meaningfulness and quality of life were better among women compared to men. The salutogenic approach is suitable for exploring the quality of life in the context of unemployment. Unemployed persons should be encouraged to engage in activities, voluntary work, for instance, that would increase their resources, enhance their quality of life, and contribute to re-employment.
\end{abstract}

Keywords Salutogenesis · Quality of life · Health · Work ability · Meaningfulness · Unemployed

\section{Introduction}

Quality of life can be considered as an indicator of holistic well-being and satisfaction in life. Self-determination, social inclusion, and social relationships define individual's quality of life, experienced by emotional, physical, and material dimensions of well-being. One's quality of life is affected by their attitudes, experiences, and status in cultural and value context. These are in relation to the goals, expectations, requirements, and concerns of an individual (Poduzov and Yazykova 2019; Schalock et al. 2016). Quality of life reflects a person's satisfaction with achievements in life (Poduzov and Yazykova 2019) and can also be seen as a process that aims to realize their potential (Reinders and Schalock 2014). This potential is narrowed by unemployment which affects deeply the experiences

Marja Hult

marja.hult@iki.fi

1 Department of Nursing Science, University of Turku, Joukahaisenkatu 3-5, 20520 Turku, Finland

2 Department of Nursing Science, University of Eastern Finland, Kuopio, Finland 
and status of an individual, and thereby weakens the quality of life (Norström et al. 2019; Worach-Kardas and Kostrzewski 2014).

Unemployment is one of the major individual and social concerns in high-income countries, such as Finland. During the recent economic recovery, the unemployment rate has decreased in Finland, but is still one of the highest in Europe (Eurostat 2019). Unemployment and specifically prolonged unemployment associates with health impairments (Gebel and Voßemer 2014; McKee-Ryan et al. 2005; Paul and Moser 2009), limited work ability (Hult et al. 2019; Kerätär and Karjalainen 2010; Szlachta et al. 2012), and decreased quality of life (Worach-Kardas and Kostrzewski 2014). Although the number of unemployed people in Finland has decreased, that of long-term unemployed (unemployment duration at least a year) has remained high. This is partly due to the fact that people with health problems are at risk of becoming unemployed (Porru et al. 2019; Wagenaar et al. 2015; van Rijn et al. 2014), and they are less likely to find a new job (Nwaru et al. 2016). It was found, indeed, that only $15 \%$ of a sample of Finnish long-term unemployed was able to work (Kerätär et al. 2016). Recently, there appears to be a worrying increase in health inequalities between the unemployed and the employed (Shahidi et al. 2018). It is important to examine and promote health, work ability, and quality of life of unemployed persons and thus, to improve their employment opportunities.

\section{Background}

Salutogenic approach in health promotion field emphasizes the positive health and individuals' strengths and resources for gaining and maintaining a balance between resources and life stressors; that is to say, how to stay healthy. The approach is holistic and underlines the individual's capacity for adaptation, which, when facing unemployment, is essential. Even though salutogenic approach primarily stresses the origin of good health, the ultimate goal is good life that can be conceptualized as the quality of life. Salutogenesis focuses on resources a person can mobilize when facing life events that potentially have negative consequences (Antonovsky 1988, 1996).

The core concept of the salutogenic model is a sense of coherence that can be explained as a continuing trust that both internal and external life events are predictable and meaningful. It is formed by three components: comprehensibility, manageability, and meaningfulness. In the context of unemployment, meaningfulness is the most important element of sense of coherence for several reasons. Meaningfulness stands for motivation that makes facing the adversity of life worth investing and engaging (Sollerhed et al. 2005). It helps in promoting healthy lifestyle because of its role as a mediator between positive effects of self-esteem and self-efficacy and health behaviours (Wiesmann and Hannich 2011). For the unemployed persons, motivation is crucial in commitment to job seeking and skills development.

One source of meaningfulness during unemployment is a meaningful time-structure and activities that replace time spent in a workplace. Activities that increase unemployed persons' perception of spending time effectively are beneficial for mental health (Goodman et al. 2016). Yet, unemployed persons engage more often in passivating non-directed use of time that associates with poor health (Scanlan et al. 2011). During unemployment, reduced opportunities to participate in decision-making also decline one's perception of life as meaningful (Antonovsky 1988; Vastamäki et al. 2009). Life experiences during childhood shape one's sense of coherence that continues to develop in adulthood (Antonovsky 1988). 
A supportive intervention for unemployed job seekers succeeded to strengthen the participants' sense of coherence (Vastamäki et al. 2009). According a salutogenic model of health, the level of sense of coherence determines how effectively a person can mobilize their own resources or those that are available to him or her (Mittelmark and Bauer 2017).

In this study, we apply salutogenic model of the origin of good health to explain quality of life among unemployed persons. As the most important life experiences affecting health, work ability and quality of life of unemployed persons we bring in age and unemployment duration. With higher age health problems increase and work ability weakens among unemployed persons (Laiho et al. 2010; Szlachta et al. 2012; Vastamäki et al. 2014). However, age is associated with higher levels of perceived meaningfulness and better quality of life (Hult 2019). Unemployment duration is considered long-term for a duration of more than 1 year. Given that the re-employment rate in Finland is rapid, nearly $90 \%$ of job seekers within a year (OECD 2018), re-employment prospects for long-term unemployed persons are poor. It was found that among long-term unemployed, two thirds had a mental disorder that hinders re-employment and more than one third were actually eligible for disability pension (Kerätär et al. 2016). Furthermore, long-term unemployed persons have poorer quality of life compared to short-term unemployed, i.e., those who have been unemployed under a year (Worach-Kardas and Kostrzewski 2014; Yang et al. 2016).

Wanberg (2012) summarises deleterious consequences of unemployment for quality of life including changes in social status and in both work and family roles, and in timestructure. Also, loss of self-concept and identity, decreased social contacts, financial distress, and uncertainty about the future have their role in weakening quality of life (Wanberg 2012). Correspondingly, loss of underlying consequences of work that go beyond earning a living has detrimental effects on mental health. Jahoda defined these consequences as time structure, social contacts, commitment to shared goals, personal status and identity, and regular activity in her latent deprivation theory (Jahoda 1981), which is one the most established of theories that explain the harmful effects of unemployment on wellbeing. Interestingly, a contradictory finding shows better quality of life among unemployed nurses compared to those at work (Czekirda et al. 2017). Presumably, this only indicates the presence of high physical, mental, and social load factors in the working environment of nurses.

Health-related quality of life measured as quality-adjusted life year (QALY) scores among unemployed persons was lower compared to the employed in a recent study, and the effect of unemployment was most negative among men, those who are married, and young persons (Norström et al. 2019). Van der Meer and colleagues (2014) found that men suffer more from the negative effects of unemployment due to their traditional role as a breadwinner. Also, men have tendency to use more self-blame, other-blame, and catastrophizing, and to use less perspective taking strategies than women when coping with unemployment (Extremera and Rey 2014). However, the negative effects of unemployment are individual and contextual. For instance, negative effects are less severe in countries which offer better unemployment benefits compared to countries offering lower benefits (Bergqvist et al. 2013; Tøge 2016). Nevertheless, in Protestant cultures unemployed people suffer more than in the other cultures because of the central role of work in identity and status (van Hoorn and Maseland 2013).

Resources of quality of life include health and work ability, as they represent alongside with quality of life, an overall wellbeing of unemployed persons in this study. Good work ability is one of the most important individual factors considering reemployment (McGonagle et al. 2015; Wagenaar et al. 2015) and is strongly influenced by a health status (Hult et al. 2018, 2019; Kerätär and Karjalainen 2010; Kerätär et al. 2016; Szlachta et al. 2012). A perceived work ability during unemployment reflects 
comprehensively individual, social, environmental, and societal aspects (Lederer et al. 2014), and can be considered as a lifelong process. Work ability and quality of life are positively connected among both employed (Tavakoli-Fard et al. 2016) and unemployed persons (Hult et al. 2018). These above-mentioned studies were cross-sectional; that is to say, they revealed no causal relations, but we assume that work ability is part of a wider perception of overall wellbeing and quality of life. According to the applied theoretical framework, we have described the hypothetical model of quality of life among unemployed adults (Fig. 1).

The aim of the study was to test factors predicting quality of life among unemployed adults with a model based on salutogenic approach (Fig. 1). The following hypotheses were set:

1. Age relates positively to meaningfulness and quality of life, but negatively to health and work ability,

2. Unemployment duration relates negatively to meaningfulness, health, work ability, and quality of life,

3. Meaningfulness relates positively to health, work ability, and quality of life,

4. Health relates positively to work ability,

5. Health and work ability both relate positively to quality of life.

\section{Data and Methods}

\subsection{Participants}

Participants of this study were obtained from the nationwide Finnish Regional Health and Well-being Study (ATH), which is ongoing from the year 2009. The ATH study (the FinSote survey since 2017) was coordinated by the National Institute for Health and Welfare. The sample $(n=76,000)$ of people aged 20 and upwards stratified by region, age, and gender, was randomly drawn from the National Population Register. They were sent an invitation letter with an information leaflet of the study. People were able to participate by a mailed questionnaire or by an Internet-based survey. The language options for the survey were Finnish, Swedish, English, and Russian. Responding to the survey was considered as giving an informed consent. Of the sample, $40.3 \%$ people $(n=30,598)$ participated between January 2014 and January 2015. Among them, 1832 persons aged 20-65 were unemployed or laid-off.

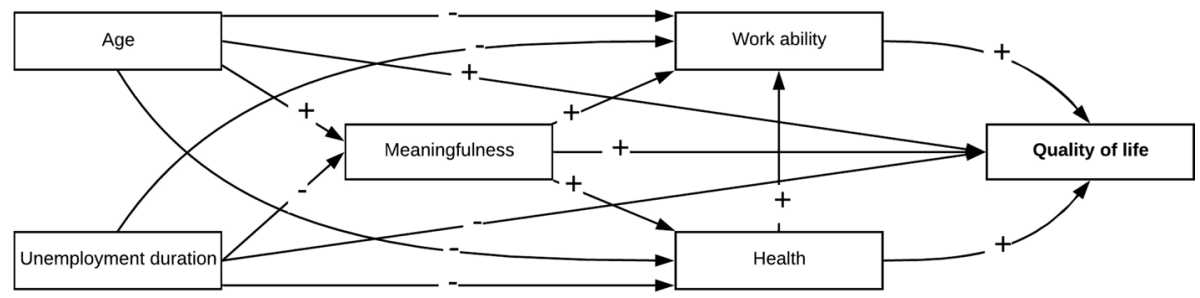

Fig. 1 Hypothesised model of factors predicting quality of life among unemployed adults 


\subsection{Data Collection}

The questionnaire contained the following themes: health, wellbeing, functional and working capacity, lifestyle, and services. This study used self-reported information on meaningfulness, health, work ability, and quality of life. Of sociodemographic factors, age, obtained from the National Population Register, and unemployment duration, which was self-reported, were applied in the analyses.

Quality of life was measured with EUROHIS-QOL $(\alpha=0.86)$ scores per item ranging from 1 to 5 giving a total score from 8 to 40 . The index consisted of eight items: overall quality of life, satisfaction with health, daily activities, self-esteem, personal relationships, living environment, energy, and economic resources. The total score was returned to the original scale by calculating a mean, and a score of 4 or more indicated a good quality of life.

Meaningfulness was measured with a question of the extent a person feels his or her life is meaningful in a Likert scale from 1 (not at all) to 5 (completely). Health was measured as Self-rated health (SRH) with a Likert-scale from 1 (poor) to 5 (good). As Antonovsky (1988) defined health as a qualitative continuum, SRH is also capable to separate positive and negative SRH into two different concepts (Reile and Leinsalu 2013). Work Ability Score (WAS) was used to measure work ability. One question assessed current work ability compared to the best in a lifetime in a scale from 0 to 10 . Participants evaluated their work ability in their last recent jobs.

\subsection{Data Analysis}

Descriptive statistics were used to describe participants. Differences between genders were examined with independent samples $t$ test. Means were calculated for eight dimensions of quality of life. Correlations between continuous study variables were produced as Pearson's coefficients. Correlations between continuous variables and variables measured with the ordinal scale, and two variables measured with ordinal scales were calculated as Spearman's rho. Path analyses with were applied to test the study hypotheses. Only full data $(n=1158)$ were used for analysis. When full data was compared to data from all unemployed respondents to the survey, there were no differences in the study variables. Fit indices that were used to determine the model fit were Normal Fit Index (NFI) and Comparative Fit Index $(\mathrm{CFI})>0.95$, and Root Mean Square Error of Approximation (RMSEA) $<0.05$ (Hooper et al. 2008). The bootstrapping method (number of samples $=2000$ ), with bias-corrected confidence intervals of $95 \%$, was used to test the significance of direct and total effects. SPSS version 25 was used to produce descriptive statistics and correlations. Path analyses were conducted with AMOS.

\section{Results}

\subsection{Characteristics of Unemployed Participants}

Among the participants $(\mathrm{n}=1158), 52.1 \%$ were male and $60.0 \%$ were married or cohabiting. The mean age was 46.3 years $(\mathrm{SD}=13.2)$ ranging from 20 to 68 years. One fifth of the participants $(21.5 \%)$ had young children under 18 years living in a 
Table 1 Characteristics of unemployed participants by genders

\begin{tabular}{lllll}
\hline & $\begin{array}{l}\text { All }(\mathrm{n}=1158) \\
\text { Mean (SD) }\end{array}$ & $\begin{array}{l}\text { Men }(\mathrm{n}=603) \\
\text { Mean (SD) }\end{array}$ & $\begin{array}{l}\text { Women }(\mathrm{n}=555) \\
\text { Mean (SD) }\end{array}$ & $p$ \\
\hline Age (years) & $46.31(13.20)$ & $46.32(13.14)$ & $46.31(13.28)$ & 0.995 \\
$\begin{array}{l}\text { Unemployment duration } \\
\text { (months) }\end{array}$ & $16.64(22.37)$ & $17.37(21.57)$ & $15.85(23.20)$ & 0.251 \\
$\begin{array}{l}\text { Meaningfulness } \\
\text { Health }\end{array}$ & $3.47(1.00)$ & $3.31(1.02)$ & $3.64(0.95)$ & $0.000^{*}$ \\
Work ability & $3.65(0.98)$ & $3.61(1.00)$ & $3.70(0.96)$ & 0.148 \\
Quality of life & $7.56(2.24)$ & $7.53(2.24)$ & $7.60(2.24)$ & 0.600 \\
\hline
\end{tabular}

$* p<0.05$

Table 2 Means (SD) for dimensions of quality of life by genders

\begin{tabular}{lllll}
\hline & $\begin{array}{l}\text { All }(\mathrm{n}=1158) \\
\text { Mean (SD) }\end{array}$ & $\begin{array}{l}\text { Men (n=603) } \\
\text { Mean (SD) }\end{array}$ & $\begin{array}{l}\text { Women (n=555) } \\
\text { Mean (SD) }\end{array}$ \\
\hline Overall quality of life & $3.62(0.83)$ & $3.52(0.85)$ & $3.73(0.81)$ & $0.000^{*}$ \\
Satisfaction with health & $3.47(1.03)$ & $3.46(1.00)$ & $3.48(1.05)$ & 0.676 \\
Satisfaction with ability to perform daily & $4.10(0.93)$ & $4.05(0.90)$ & $4.15(0.97)$ & 0.085 \\
$\quad$ & & & & 0.777 \\
activities & $3.61(0.96)$ & $3.60(0.95)$ & $3.62(0.98)$ & $0.044^{*}$ \\
Satisfaction with oneself & $3.71(0.98)$ & $3.66(0.95)$ & $3.77(1.01)$ & $0.004^{*}$ \\
Satisfaction with personal relationships & $3.85(0.87)$ & $3.78(0.86)$ & $3.93(0.87)$ & 0.830 \\
Having enough energy for everyday life & $3.93(1.02)$ & $3.92(1.03)$ & $3.93(1.01)$ & 0.165 \\
Having enough money to meet the one's needs & $3.03(1.24)$ & $2.98(1.24)$ & $3.08(1.23)$ & \\
\hline
\end{tabular}

$* p<0.05$

household. The average length of education was $13.85(\mathrm{SD}=3.81)$ years spent in basic or professional training. The majority $(88.3 \%)$ had been working as a salary or wage earner in a previous job. Less than half of the participants $(39.7 \%)$ felt that they would not have been able to continue working until their official retirement age for their health. Over half $(54.8 \%)$ of the participants were short-term unemployed (unemployment duration under 12 months). Half of the participants (49.1\%) felt their life to be mostly or completely meaningful (scores 4 and 5). Health was perceived good (scores 4 and 5 ) by $58.7 \%$ of the participants. Two thirds $(63.4 \%)$ of the participants perceived good work ability (score 8 or more). Characteristics of participants by study variables by genders are presented in Table 1 . Women perceived significantly higher meaningfulness and better quality of life than men.

A minority of the participants (39.4\%) had a good quality of life. Among the dimensions of quality of life, participants were most satisfied with their ability to perform daily activities (mean 4.10) and less satisfied with their financial situation (mean 3.03). When comparing men and women, women were more satisfied than men with their overall quality of life, personal relationships, and living environment (Table 2). 
Table 3 Correlations between study variables

\begin{tabular}{|c|c|c|c|c|c|c|}
\hline & 1 & 2 & 3 & 4 & 5 & 6 \\
\hline 1 Age & 1.00 & & & & & \\
\hline 2 Unemployment duration & $0.24 *$ & 1.00 & & & & \\
\hline 3 Meaningfulness & $0.09 *$ & $-0.09 *$ & 1.00 & & & \\
\hline 4 Health & $-0.11^{*}$ & $-0.14 *$ & $0.32 *$ & 1.00 & & \\
\hline 5 Work ability & $-0.16^{*}$ & $-0.26^{*}$ & $0.30 *$ & $0.61 *$ & 1.00 & \\
\hline 6 Quality of life & $0.14 *$ & $-0.12 *$ & $0.57 *$ & $0.56^{*}$ & $0.47 *$ & 1.00 \\
\hline
\end{tabular}

$* p<0.01$

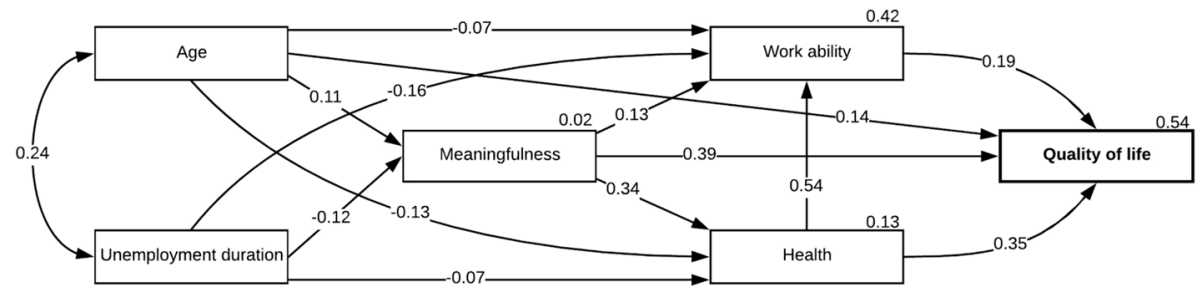

Fig. 2 Final model of factors predicting quality of life among unemployed adults. Paths are presented with standardized regression weights, all significant at the level $p<0.05$

\subsection{Correlations Between Study Variables}

Bivariate correlations between study variables were all significant at the level $p<0.01$ (Table 3). Correlations between meaningfulness and quality of life, health and work ability, and health and quality of life were strong $(r>0.5)$. Age correlated negatively with health and work ability. Unemployment duration, in turn, correlated negatively with meaningfulness, health, work ability, and quality of life.

\subsection{A Model of Factors Predicting Quality of Life}

The hypothesized model did not fit the data as such, since $\left(\chi^{2}[1]=71.110, p=0.000\right.$, $\mathrm{NFI}=0.961, \mathrm{CFI}=0.961$, RMSEA $=0.246$ (95\% CI 0.200-0.296), but some adjustments were needed. A path from unemployment duration to quality of life was removed, because it was not significant. To further improve the model, age and unemployment duration were allowed to correlate. After these adjustments, the final model fit was excellent: $\chi^{2}$ $[1]=1.215, p=0.270, \mathrm{NFI}=0.999, \mathrm{CFI}=1.000, \mathrm{RMSEA}=0.014(95 \%$ CI $0.000-0.081)$. The model explained $54 \%$ of the variance of quality of life, $42 \%$ of work ability, $13 \%$ of health and $2 \%$ of the variance of meaningfulness (Fig. 2).

Table 4 shows all the direct and total effects of the final model obtained by bootstrapping. It can be seen that even though unemployment duration did not have a direct effect on quality of life, the total effect is negative. Therefore, the effect of unemployment duration on quality of life is completely mediated by the other variables in the model. All the other mediation effects were partial. Health mediated the effect of meaningfulness on work 
Table 4 Direct and total effects as standardized regression weights

\begin{tabular}{lcc}
\hline & Direct effect $(\beta)^{*}$ & Total effect $(\beta)^{*}$ \\
\hline Age $\rightarrow$ Meaningfulness & 0.11 & \\
Age $\rightarrow$ Health & -0.13 & -0.09 \\
Age $\rightarrow$ Work ability & -0.07 & -0.11 \\
Age $\rightarrow$ Quality of life & 0.14 & 0.14 \\
Unemployment duration $\rightarrow$ Meaningfulness & -0.12 & \\
Unemployment duration $\rightarrow$ Health & -0.07 & -0.11 \\
Unemployment duration $\rightarrow$ Work ability & -0.16 & -0.23 \\
Unemployment duration $\rightarrow$ Quality of life & & -0.13 \\
Meaningfulness $\rightarrow$ Health & 0.34 & \\
Meaningfulness $\rightarrow$ Work ability & 0.13 & 0.31 \\
Meaningfulness $\rightarrow$ Quality of life & 0.39 & 0.57 \\
Health $\rightarrow$ Work ability & 0.54 & 0.46 \\
Health $\rightarrow$ Quality of life & 0.35 & \\
Work ability $\rightarrow$ Quality of life & 0.19 & \\
\hline
\end{tabular}

*Significant at the level $p<0.05$

ability by strengthening its effect $(\beta=0.31)$. Also, the effect of meaningfulness on quality of life was mediated by health and work ability giving a total effect of $\beta=0.57$. And finally, work ability mediated partly the effect of health on quality of life $(\beta=0.46)$.

Hypothesis 1 was confirmed, since higher age associated with higher meaningfulness and better quality of life, and poorer health and work ability. Hypothesis 2 was only partially confirmed, because longer unemployment duration associated with less meaningfulness, and poorer health and work ability, but did not have a direct effect on quality of life. However, a mediated total effect was negative (Table 4). Hypothesis 3-5 were confirmed showing a positive association of meaningfulness with health, work ability and quality of life (hypothesis 3), a positive association between health and work ability (hypothesis 4), and positive relations of health and work ability to quality of life (hypothesis 5).

\section{Discussion}

\subsection{Salutogenic Approach to Quality of Life Studies}

The need for labor is increasing in many sectors due to the aging workforce, therefore, the employment rate should be higher in Finland. However, there are many unemployed people who do not succeed in re-employment due to various reasons, and thus, are at risk of marginalization. According to salutogenesis, whether a person is employed or unemployed, it is important to promote good life. This is the first study, to our knowledge, to extend the concepts and positive health model of salutogenesis to cover quality of life. We show that perceiving life as meaningful is significantly associated with health, work ability and quality of life, and therefore, may act as a fundamental resource for wellbeing. In our model, health and work ability significantly associate with quality of life forming a solid basis for it. Results show that our model fitted perfectly to the data, and this advocates the use of 
salutogenesis more widely in population health studies and particularly among unemployed people.

\subsection{Quality of Life and the Impact of Meaningfulness}

Alarmingly low proportion of unemployed persons (40\%) had good quality of life. When good health and self-esteem, satisfaction with spare time, good social relations, and participation in collaborative decision making are found to promote good quality of life during unemployment (Worach-Kardas and Kostrzewski 2014), results show that unemployed persons lack these resources. Indeed, slightly under $60 \%$ of the participants perceived good health and a little over $60 \%$ perceived good work ability. As our results also indicate, good health promotes good work ability which is the most individual factor in successful reemployment (Ferreira et al. 2015). Rapid re-employment of the unemployed should be supported by appropriate and efficient employment services, since among other benefits, re-employment enhances quality of life, and recovery continues for months (Carlier et al. 2013; van Rijn et al. 2016).

Manifest benefit of work is financial compensation. Among components of quality of life, unemployed participants were least satisfied with their financial situation. Our result is supported by previous studies among the unemployed (Worach-Kardas and Kostrzewski 2014), and the employed (Powdthavee 2010; Rojas 2011). These studies confirm that the financial situation of the household is the most important factor influencing the evaluation of the quality of life. Specifically, the worse the economic situation, the lower the quality of life. Financial deprivation is the major consequence of unemployment that causes decline in wellbeing according to recent studies (Brydsten et al. 2018; González-Marín et al. 2018; López Del Amo González et al. 2018).

Another worrying finding of this study reveals that only a half of the unemployed persons perceived meaningfulness in life. In our model, meaningfulness had the strongest effect on quality of life. An earlier study found that unemployed persons had significantly lower scores on meaningfulness compared to the employed (Hult et al. 2019). This confirms the role of work as an important source of meaning in life (Jahoda 1981). Unemployed persons should be encouraged to engage in activities that could compensate for the latent functions of work, and which are valued by the society. Voluntary work could be one of these kinds of activities that increase feelings of belonging and participation. In general, all kinds of social group activities are recommended, because they provide an opportunity to extend their networks which are always crucial in job seeking.

\subsection{Decreased Health and Work Ability}

Perceived health was good by less than $60 \%$ of the participants while same data shows that good health was perceived by over $70 \%$ of all working age people (Murto et al. 2016). This finding is in line with numerous studies demonstrating the relation of poor health and unemployment (e.g. Stauder 2019). Our results cannot supply evidence for whether unemployment is caused by poor health or poor health is a consequence of unemployment. However, improvement in health, and particularly in mental health, is an important prerequisite to successful reintegration into the job market, and also, to social participation (Limm et al. 2015). It is suggested that positive health outcomes could be achieved when an unemployed person is able to positively reassess and refocus, change their perspective and plan (Extremera and Rey 2014). Salutogenesis involves the idea that an individual's ability to 
be flexible and to adapt contribute to positive mental health. Flexibility and adaptability are desirable qualities in current working life. These qualities are especially needed when faced with uncertainty or unemployment in working life. Experiences of control, comprehensibility, and meaningfulness in life, which may erode in uncertainty, shape human health and resources. Our results highlight the role of meaningfulness in overall wellbeing and mental health, and unemployed persons should be encouraged to seek meaningful activities to compensate for time spent in work.

Work ability among this study participants was weaker compared to whole population (Murto et al. 2016), which is supported by previous studies (Hult et al. 2019). Work ability was strongly associated with health and quality of life. Even though our data were crosssectional, we propose that good health is required for good work ability, and that both factors have a positive effect on quality of life, i.e., they are important resources of it. Furthermore, good work ability, alongside with active job seeking, increase chances for successful re-employment (Brouwer et al. 2015). Unlike those in employment, the unemployed are excluded from work-related health and work ability promotion measures. These measures would be particularly important for the unemployed, who have a lower ability to work than those in employment.

\subsection{Gender Differences in Quality of Life}

We examined meaningfulness, health, work ability and quality of life by genders, since there is strong evidence that men tend to suffer more from the negative effects of unemployment than women. Indeed, our results also showed that women perceived higher meaningfulness and better quality of life than men. Women are accustomed to being out of work with having children and therefore may find meaningful activities with their family or social networks. It is found that being single associates with poor health and weakened wellbeing among unemployed persons (van der Meer 2014), but this finding did not appear in our results; there were no differences in marital status between men and women. However, women were more satisfied with their personal relationships than men according to our results. Unemployed women probably have larger social networks and they might participate more in voluntary work more than men. In addition to the social networks, one source of meaningfulness for women can be physical exercise. Women tend to increase the amount of exercise when they become unemployed, whereas men do not increase their activity (Gough 2017).

\subsection{Strengths and Limitations}

Our study expanded the application of salutogenic approach to the quality of life among unemployed persons, which may be considered as a strength. This novel theoretical starting point, combined with population-level data, brings a new perspective on the overall wellbeing of the unemployed. Theoretical model transferred to empirical data gave an excellent model fit, and the final model succeeded to explain $54 \%$ of the variance of quality of life. The data were population-based, so the results are generalizable in Finland and, most likely, in countries with similar culture and, for instance, level of unemployment benefits.

Instruments we used to measure quality of life, health, and work ability are widely used and found reliable, and we used only full data of each respondent. To measure quality of life we used EUROHIS-QOL, a shortened version of WHOQOL-BREF instrument with which it correlates strongly (da Rocha et al. 2012). In this study, the 
Cronbach's alpha coefficient for quality of life was 0.86 . Self-rated health (SRH) is one of the most widely used indicators in population studies, and it is found reliable in measuring current state of health predicting mortality and morbidity (Latham and Peek 2013; Szybalska et al. 2018). Subjective WAS measures work ability as reliably as more comprehensive Work Ability Index (Ahlstrom et al. 2010; El Fassi et al. 2013).

Of course, there are some limitations worth mentioning. The response rate was $40 \%$ which may have an impact to the results. The analysis of non-participants revealed that youngest men were most likely not to participate. Non-response rates were also higher among unmarried men compared to married and among people not speaking Finnish. People who had completed education higher than basic or vocational education were participating most actively (Härkänen et al. 2014). The analysis shows that young unemployed men were possibly under-represented in the data, thus suggesting that our results are not generalizable at the population. Our data were cross-sectional and do not allow to draw causal conclusions. Therefore, to examine causal inferences, longitudinal settings and intervention studies are needed to address wellbeing and quality of life among unemployed people.

\section{Conclusion}

This study shows the applicability of salutogenic approach in the context of overall wellbeing and quality of life among unemployed persons. Results highlight the significance of perceiving life as meaningful to good health and work ability and, notably, to good quality of life. Further, in terms of salutogenesis, health stand for important resource for work ability, and they both are resources of quality of life. Men perceived less meaningfulness and had poorer quality of life, so measures and interventions should be targeted specifically for them. On the whole, unemployed persons should be encouraged to engage in meaningful activities that include social support and networking, since they are substantial sources of meaningfulness. Unemployed persons should be provided programs and interventions to promote their health and work ability which further improve the quality of life and contribute to re-employment.

Author Contributions MH: The conception and design of the study and analysis and interpretation of data, drafting the article or revising it critically for important intellectual content, final approval of the version to be submitted. AMP: Drafting the article or revising it critically for important intellectual content, final approval of the version to be submitted. TS: Drafting the article or revising it critically for important intellectual content, final approval of the version to be submitted.

Funding Open access funding provided by University of Turku (UTU) including Turku University Central Hospital. The authors received no specific funding for this work.

\section{Compliance with Ethical Standards}

Conflict of interest No conflict of interest has been declared by the authors.

Ethical Approval The ethics committee approval was obtained from the National Institute of Health and Welfare for the original ATH study in 2009 and no separate approval was required for this study. 
Open Access This article is licensed under a Creative Commons Attribution 4.0 International License, which permits use, sharing, adaptation, distribution and reproduction in any medium or format, as long as you give appropriate credit to the original author(s) and the source, provide a link to the Creative Commons licence, and indicate if changes were made. The images or other third party material in this article are included in the article's Creative Commons licence, unless indicated otherwise in a credit line to the material. If material is not included in the article's Creative Commons licence and your intended use is not permitted by statutory regulation or exceeds the permitted use, you will need to obtain permission directly from the copyright holder. To view a copy of this licence, visit http://creativecommons.org/licenses/by/4.0/.

\section{References}

Ahlstrom, L., Grimby-Ekman, A., Hagberg, M., \& Dellve, L. (2010). The work ability index and singleitem question: Associations with sick leave, symptoms, and health-A prospective study of women on long-term sick leave. Scandinavian Journal of Work, Environment \& Health, 36(5), 404-412. https://doi.org/10.5271/sjweh.2917.

Antonovsky, A. (1988). Unraveling the mystery of health. How people manage stress and stay well. Hoboken: Jossey Bass Publishers.

Antonovsky, A. (1996). The salutogenic model as a theory to guide health promotion. Health Promotion International, 11(1), 11-18. https://doi.org/10.1093/heapro/11.1.11.

Bergqvist, K., Yngwe, M. Å., \& Lundberg, O. (2013). Understanding the role of welfare state characteristics for health and inequalities-An analytical review. BMC Public Health. https://doi. org/10.1186/1471-2458-13-1234.

Brouwer, S., Bakker, R. H., \& Schellekens, J. M. H. (2015). Predictors for re-employment success in newly unemployed: A prospective cohort study. Journal of Vocational Behavior, 89, 32-38. https:// doi.org/10.1016/j.jvb.2015.04.001.

Brydsten, A., Hammarström, A., \& San Sebastian, M. (2018). Health inequalities between employed and unemployed in northern Sweden: A decomposition analysis of social determinants for mental health. International Journal for Equity in Health, 17(1), 1-11. https://doi.org/10.1186/s1293 9-018-0773-5.

Carlier, B. E., Schuring, M., Lotters, F. J. B., Bakker, B., Borgers, N., \& Burdorf, A. (2013). The influence of re-employment on quality of life and self-rated health, a longitudinal study among unemployed persons in the Netherlands. BMC Public Health, 13, 503. https://doi.org/10.1186/1471-2458-13-503.

Czekirda, M., Chruściel, P., Czekirda, N., \& Jarosz, M. J. (2017). Psychosocial aspect of quality of life among working and unemployed nurses and midwives. Annals of Agricultural and Environmental Medicine, 24(3), 472-476. https://doi.org/10.5604/12321966.1235172.

da Rocha, N. S., Power, M. J., Bushnell, D. M., \& Fleck, M. P. (2012). The EUROHIS-QOL 8-item index: Comparative psychometric properties to its parent WHOQOL-BREF. Value in Health, 15(3), 449-457. https://doi.org/10.1016/j.jval.2011.11.035.

El Fassi, M., Bocquet, V., Majery, N., Lair, M. L., Couffignal, S., \& Mairiaux, P. (2013). Work ability assessment in a worker population: Comparison and determinants of Work Ability Index and Work Ability score. BMC Public Health, 13(1), 1-10. https://doi.org/10.1186/1471-2458-13-305.

Eurostat. (2019). Unemployment by sex and age-Annual average. Retrieved March 12, 2019 from http:// appsso.eurostat.ec.europa.eu/nui/show.do?dataset=une_rt_a\&lang=en.

Extremera, N., \& Rey, L. (2014). Health-related quality of life and cognitive emotion regulation strategies in the unemployed: A cross-sectional survey. Health and Quality of Life Outcomes, 12(1), 1-9. https:// doi.org/10.1186/s12955-014-0172-6.

Ferreira, J. A., Reitzle, M., Lee, B., Freitas, R. A., Santos, E. R., Alcoforado, L., et al. (2015). Configurations of unemployment, reemployment, and psychological well-being: A longitudinal study of unemployed individuals in Portugal. Journal of Vocational Behavior, 91, 54-64. https://doi.org/10.1016/j. jvb.2015.09.004.

Gebel, M., \& Voßemer, J. (2014). The impact of employment transitions on health in Germany. A difference-in-differences propensity score matching approach. Social Science and Medicine, 108, 128-136. https://doi.org/10.1016/j.socscimed.2014.02.039.

González-Marín, P., Puig-Barrachina, V., Cortès-Franch, I., Bartoll, X., Artazcoz, L., Malmusi, D., et al. (2018). Social and material determinants of health in participants in an active labor market program in Barcelona. Archives of Public Health, 76(1), 1-8. https://doi.org/10.1186/s13690-018-0310-4. 
Goodman, W. K., Geiger, A. M., \& Wolf, J. M. (2016). Leisure activities are linked to mental health benefits by providing time structure: Comparing employed, unemployed and homemakers. Journal of Epidemiology and Community Health, 71(1), 4-11. https://doi.org/10.1136/jech-2016-207260.

Gough, M. (2017). A couple-level analysis of participation in physical activity during unemployment. SSM-Population Health, 3(March), 294-304. https://doi.org/10.1016/j.ssmph.2017.03.001.

Härkänen, T., Kaikkonen, R., Virtala, E., \& Koskinen, S. (2014). Inverse probability weighting and doubly robust methods in correcting the effects of non-response in the reimbursed medication and selfreported turnout estimates in the ATH survey. BMC Public Health, 14, 1.

Hooper, D., Coughlan, J., \& Mullen, M. R. (2008). Structural equation modelling: Guidelines for determining model fit. Electronic Journal of Business Research Methods, 6(1), 53-60. https://doi.org/10.21427 /D79B73.

Hult, M. (2019). The work ability and health of unemployed persons. Focusing on promoting factors (pp. 50-51). Dissertations in Health Sciences. University of Eastern Finland.

Hult, M., Pietilä, A. M., Koponen, P., \& Saaranen, T. (2018). Good work ability among unemployed individuals: Association of sociodemographic, work-related and well-being factors. Scandinavian Journal of Public Health, 46(3), 375-381. https://doi.org/10.1177/1403494817720103.

Hult, M., Pietilä, A.-M., \& Saaranen, T. (2019). Improving employment opportunities of the unemployed by health and work ability promotion in Finland. Health Promotion International. https:// doi.org/10.1093/heapro/daz048.

Jahoda, M. (1981). Work, employment, and unemployment: Values, theories, and approaches in social research. American Psychologist, 36(2), 184-191. https://doi.org/10.1037/0003-066X.36.2.184.

Kerätär, R., \& Karjalainen, V. (2010). High level of untreated mental disturbances among the long-term unemployed. Suomen Lääkärilehti, 45, 3683-3690.

Kerätär, R., Taanila, A., Jokelainen, J., Soukainen, J., \& Ala-Mursula, L. (2016). Work disabilities and unmet needs for health care and rehabilitation among jobseekers: a community-level investigation using multidimensional work ability assessments. Scandinavian Journal of Primary Health Care, 34(4), 343-351. https://doi.org/10.1080/02813432.2016.1248632.

Laiho, V., Hopponen, A., Latvala, T., \& Rämö, A.-K. (2010). The working capacity of unemployed and disabled persons. Pellervo Economic Research PTT.

Latham, K., \& Peek, C. W. (2013). Self-rated health and morbidity onset among late midlife U.S. adults. The Journals of Gerontology. Series B, Psychological Sciences and Social Sciences, 68(1), 107116. https://doi.org/10.1093/geronb/gbs104.

Lederer, V., Loisel, P., Rivard, M., \& Champagne, F. (2014). Exploring the diversity of conceptualizations of work (dis)ability: a scoping review of published definitions. Journal of Occupational Rehabilitation, 24(2), 242-267. https://doi.org/10.1007/s10926-013-9459-4.

Limm, H., Heinmüller, M., Gündel, H., Liel, K., Seeger, K., Salman, R., et al. (2015). Effects of a health promotion program based on a train-the-trainer approach on quality of life and mental health of long-term unemployed persons. BioMed Research International, 2015, 1-10. https://doi. org/10.1155/2015/719327.

López Del Amo González, M. P., Benítez, V., \& Martín-Martín, J. J. (2018). Long term unemployment, income, poverty, and social public expenditure, and their relationship with self-perceived health in Spain (2007-2011). BMC Public Health, 18(1), 1-14. https://doi.org/10.1186/s12889-017-5004-2.

McGonagle, A. K., Fisher, G. G., Barnes-Farrell, J. L., \& Grosch, J. W. (2015). Individual and work factors related to perceived work ability and labor force outcomes. Journal of Applied Psychology, 100(2), 376-398. https://doi.org/10.1037/a0037974.

McKee-Ryan, F. M., Song, Z., Wanberg, C. R., \& Kinicki, A. J. (2005). Psychological and physical wellbeing during unemployment: A meta-analytic study. Journal of Applied Psychology, 90(1), 53-76. https://doi.org/10.1037/0021-9010.90.1.53.

Mittelmark, M., \& Bauer, G. (2017). The meanings of salutogenesis. In M. Mittelmark, S. Sagy, M. Eriksson, G. Bauer, J. Pelikan, B. Lindström, \& G. Espnes (Eds.), The handbook of salutogenesis (pp. 7-14). Berlin: Springer.

Murto, J., Kaikkonen, R., Pentala-Nikulainen, O., Koskela, T., Virtala, E., Härkänen, T., Koskenniemi, T., Jussmäki, T., Vartiainen, E., Koskinen, S. (2016). Aikuisten terveys-, hyvinvointi- ja palvelututkimus ATH:n perustulokset 2010-2016. Retrieved November 10, 2019 from http://www.terve ytemme.fi/ath/.

Norström, F., Waenerlund, A. K., Lindholm, L., Nygren, R., Sahlén, K. G., \& Brydsten, A. (2019). Does unemployment contribute to poorer health-related quality of life among Swedish adults? BMC Public Health, 19(1), 1-12. https://doi.org/10.1186/s12889-019-6825-y. 
Nwaru, C. A., Nygard, C.-H., \& Virtanen, P. (2016). Musculoskeletal pain and re-employment among unemployed job seekers: A three-year follow-up study. BMC Public Health, 16, 531. https://doi. org/10.1186/s12889-016-3200-0.

OECD. (2018). OECD Employment Outlook 2018. Retrieved February 1, 2019 from https://www.oecdilibrary.org/employment/oecd-employment-outlook-2018_empl_outlook-2018-en.

Paul, K. I., \& Moser, K. (2009). Unemployment impairs mental health: Meta-analyses. Journal of Vocational Behavior, 74(3), 264-282. https://doi.org/10.1016/j.jvb.2009.01.001.

Poduzov, A. A., \& Yazykova, V. S. (2019). On the possibilities of assessing the subjective quality of life. Studies on Russian Economic Development, 30(5), 523-529. https://doi.org/10.1134/s107570071 9050095.

Porru, F., Burdorf, A., \& Robroek, S. J. W. (2019). The impact of depressive symptoms on exit from paid employment in Europe: A longitudinal study with 4 years follow-up. European Journal of Public Health, 29(1), 134-139. https://doi.org/10.1093/eurpub/cky136.

Powdthavee, N. (2010). How much does money really matter? Estimating the causal effects of income on happiness. Empirical Economics, 39(1), 77-92. https://doi.org/10.1007/s00181-009-0295-5.

Reile, R., \& Leinsalu, M. (2013). Differentiating positive and negative self-rated health: Results from a cross-sectional study in Estonia. International Journal of Public Health, 58(4), 555-564. https:// doi.org/10.1007/s00038-013-0445-6.

Reinders, H. S., \& Schalock, R. L. (2014). How organizations can enhance the quality of life of their clients and assess their results: The concept of QOL enhancement. American Journal on Intellectual and Developmental Disabilities, 119(4), 291-302. https://doi.org/10.1352/1944-7558-119.4.291.

Rojas, M. (2011). The "measurement of economic performance and social progress" report and quality of life: Moving forward. Social Indicators Research, 102(1), 169-180. https://doi.org/10.1007/ s11205-010-9737-x.

Scanlan, J. N., Bundy, A. C., \& Matthews, L. R. (2011). Promoting wellbeing in young unemployed adults: The importance of identifying meaningful patterns of time use. Australian Occupational Therapy Journal, 58(2), 111-119. https://doi.org/10.1111/j.1440-1630.2010.00879.x.

Schalock, R. L., Verdugo, M. A., Gomez, L. E., \& Reinders, H. S. (2016). Moving us toward a theory of individual quality of life. American Journal on Intellectual and Developmental Disabilities, 121(1), 1-12. https://doi.org/10.1352/1944-7558-121.1.1.

Shahidi, F. V., Muntaner, C., Shankardass, K., Quiñonez, C., \& Siddiqi, A. (2018). Widening health inequalities between the employed and the unemployed: A decomposition of trends in Canada (20002014). PLoS One, 13(11), 1-23. https://doi.org/10.1371/journal.pone.0208444.

Sollerhed, A. C., Ejlertsson, G., \& Apitzsch, E. (2005). Predictors of strong sense of coherence and positive attitudes to physical education in adolescents. Scandinavian Journal of Public Health, 33(5), 334-342. https://doi.org/10.1080/14034940510005833.

Stauder, J. (2019). Unemployment, unemployment duration, and health: Selection or causation? European Journal of Health Economics, 20(1), 59-73. https://doi.org/10.1007/s10198-018-0982-2.

Szlachta, E., Gawlik-Chmiel, B., \& Kallus, K. W. (2012). Do the long-term unemployed regard themselves as able to work? Journal of Public Health, 20(5), 505-511. https://doi.org/10.1007/s1038 9-012-0505-z.

Szybalska, A., Broczek, K., Puzianowska-Kuznicka, M., Slusarczyk, P., Chudek, J., Skalska, A., et al. (2018). Self-rated health and its association with all-cause mortality of older adults in Poland: The PolSenior project. Archives of Gerontology and Geriatrics, 79(July), 13-20. https://doi. org/10.1016/j.archger.2018.07.016.

Tavakoli-Fard, N., Mortazavi, S. A., Kuhpayehzadeh, J., \& Nojomi, M. (2016). Quality of life, work ability and other important indicators of women's occupational health. International Journal of Occupational Medicine and Environmental Health, 29(1), 77-84. https://doi.org/10.13075/ijome h.1896.00329.

Tøge, A. G. (2016). Health effects of unemployment in Europe during the great recession: The impact of unemployment generosity. International Journal of Health Services: Planning, Administration, Evaluation, 46(4), 614-641. https://doi.org/10.1177/0020731416664688.

van der Meer, P. H. (2014). Gender, unemployment and subjective well-being: Why being unemployed is worse for men than for women. Social Indicators Research, 115, 23-44. https://doi.org/10.1007/ s11205-012-0207-5.

van Hoorn, A., \& Maseland, R. (2013). Does a Protestant work ethic exist? Evidence from the wellbeing effect of unemployment. Journal of Economic Behavior \& Organization, 9, 1-12. https://doi. org/10.1016/j.jebo.2013.03.038.

Van Rijn, R. M., Carlier, B. E., Schuring, M., \& Burdorf, A. (2016). Work as treatment? The effectiveness of re-employment programmes for unemployed persons with severe mental health problems on 
health and quality of life: A systematic review and meta-analysis. Occupational and Environmental Medicine, 73(4), 275-279. https://doi.org/10.1136/oemed-2015-103121.

van Rijn, R. M., Robroek, S. J., Brouwer, S., \& Burdorf, A. (2014). Influence of poor health on exit from paid employment: A systematic review. Occupational and Environmental Medicine, 71, 295-301.

Vastamäki, J., Moser, K., \& Paul, K. I. (2009). How stable is sense of coherence? Changes following an intervention for unemployed individuals. Scandinavian Journal of Psychology, 50(2), 161-171. https://doi.org/10.1111/j.1467-9450.2008.00695.x.

Vastamäki, J., Wolff, H. G., Paul, K. I., \& Moser, K. (2014). Sense of coherence mediates the effects of low work ability on mental distress during unemployment. Journal of Workplace Behavioral Health, 29(4), 317-332. https://doi.org/10.1080/15555240.2014.956931.

Wagenaar, A. F., Kompier, M. A. J., Houtman, I. L. D., van den Bossche, S. N. J., \& Taris, T. W. (2015). Who gets fired, who gets re-hired: the role of workers' contract, age, health, work ability, performance, work satisfaction and employee investments. International Archives of Occupational and Environmental Health, 88(3), 321-334. https://doi.org/10.1007/s00420-014-0961-6.

Wanberg, C. R. (2012). The individual experience of unemployment. Annual Review of Psychology. https:// doi.org/10.1146/annurev-psych-120710-100500.

Wiesmann, U., \& Hannich, H. (2011). Salutogenic perspectives on health maintenance: The role of resistance resources and meaningfulness. GeroPsych: The Journal of Gerontopsychology and Geriatric Psychiatry, 24, 127-135. https://doi.org/10.1024/1662-9647/a000040.

Worach-Kardas, H., \& Kostrzewski, S. (2014). Quality of life and health state of long-term unemployed in older production age. Applied Research in Quality of Life, 9(2), 335-353. https://doi.org/10.1007/ s11482-013-9240-z.

Yang, X., Yao, L., Wu, H., Wang, Y., Liu, L., Wang, J., et al. (2016). Quality of life and its related factors in Chinese unemployed people: A population-based cross-sectional study. International Journal of Environmental Research and Public Health, 13(8), 1-14. https://doi.org/10.3390/ijerph13080797.

Publisher's Note Springer Nature remains neutral with regard to jurisdictional claims in published maps and institutional affiliations. 